\title{
'Krypton-85 and other airborne radioactivity measurements throughout Ireland
}

\author{
K. S mith, M. Murray, J. Wong, S.C. Long, P.A. Colgan and B. Rafferty \\ Radiological Protection Institute of Ireland, 3 Clonskeagh Square, Clonskeagh Road, \\ Dublin 14, Ireland
}

\begin{abstract}
The Radiological Protection Institute of Ireland (RPII) monitors airborne radioactivity concentrations at ten stations throughout Ireland, of which nine are equipped with low volume particulate samplers and one, in Dublin, with a high volume particulate sampler. The low volume particulate samples are assessed for total beta activity. In the period 1998-2003 the total beta activity concentrations observed have been consistently low, ranging between 0.03 and $1.33 \mathrm{mBq} \mathrm{m}^{-3}$ with a mean over all sampling sites of $0.26 \pm 0.15 \mathrm{mBq} \mathrm{m}^{-3}(n=2361)$. High volume particulate samples have been assessed for caesium-137 and beryllium-7. A mean caesium-137 activity concentration of $2.3 \pm 2.2 \mu \mathrm{Bq} \mathrm{m}{ }^{-3}(n=26)$ was observed in samples taken since 1993 while the mean beryllium-7 activity concentration over this period was $3.0 \pm 1.6 \mathrm{mBq} \mathrm{m}^{-3}(n=42)$.

In addition, air sampled at the RPII's laboratory in Dublin, is monitored for krypton-85, a radioactive noble gas, released into the environment primarily as a result of the reprocessing of nuclear fuel at installations such as Sellafield in the UK and Cogema La Hague in France. Analysis of the krypton-85 monitoring data, along with additional backward air trajectory modelling, demonstrate the influence of the reprocessing plants on the krypton-85 concentrations in Ireland.
\end{abstract}

\section{INTRODUCTION}

Radioactivity is present in the terrestrial environment due to natural processes, the testing of nuclear weapons in the atmosphere, accidents such as the Chernobyl accident and the routine discharge of radionuclides from nuclear installations. The Radiological Protection Institute of Ireland (RPII) undertakes a comprehensive programme of radioactivity monitoring in the Irish terrestrial environment [1-5]. This includes an airborne radioactivity monitoring programme and a krypton-85 monitoring programme

The results of the airborne radioactivity concentration measurements, as well as the krypton-85 monitoring, are presented and discussed in this paper.

\section{AIR MONITORING PROGRAMME}

The RPII monitors airborne radioactivity concentrations at ten stations throughout Ireland (Figure 1), of which nine are equipped with low volume particulate samplers and one, at Beggars Bush in Dublin, with a high volume particulate sampler. The low volume particulate samples are routinely assessed for total beta activity and the high volume samples for gamma emitting radionuclides such as caesium-137 and beryllium-7. This programme is undertaken in part fulfilment of the requirements specified in articles 35 and 36 of the EURATOM Treaty. As required under article 36, the results of these measurements are periodically communicated to the European Union. 


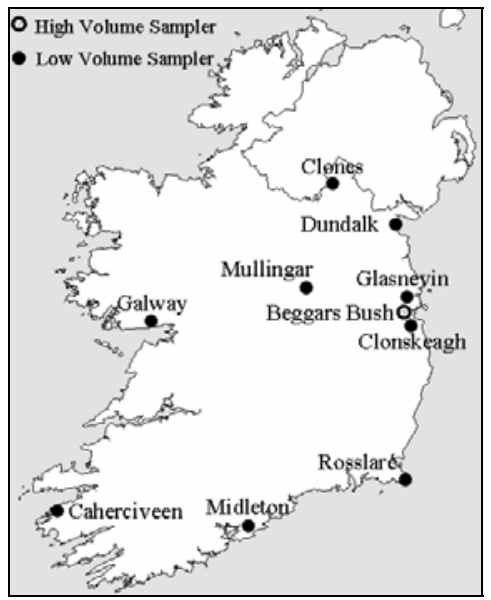

Figure 1. Airborne radioactivity sampling locations.

\subsection{Airborne particulate sampling method}

Particulates are collected using a pump to draw air continuously through a glass microfibre filter. The low volume (47 mm circular diameter) and the high volume $(25 \mathrm{~cm} \times 20 \mathrm{~cm}$ rectangular) filters are changed weekly and biweekly respectively. The volume of air sampled by the equipment, which is measured by an electronic meter, typically ranges between 500 and $1500 \mathrm{~m}^{3}$ for the low volume units and between 15,000 and $20,000 \mathrm{~m}^{3}$ for the high volume unit.

After sampling the filters are stored in a dust free environment for five days before analysis to ensure that short lived naturally occurring radionuclides have decayed below detectable levels prior to measurement. The low volume filters are analysed for gross beta activity using a gas-flow proportional counter. The high volume filters are bulked on a monthly or bimonthly basis and analysed by high-resolution gamma spectrometry.

\subsection{Results for the low volume particulate samples}

The annual ranges of gross beta activity concentrations in airborne particulates at the nine stations for 1998 to 2003 are given in Table 1 [4-5]. In the period 1998-2003, the gross beta activity concentrations have been consistently low, ranging between 0.03 and $1.33 \mathrm{mBq} \mathrm{m}^{-3}$ with a mean over all sites for the period of $0.26 \pm 0.15 \mathrm{mBq} \mathrm{m}^{-3}(n=2361)$. These low activity concentrations form part of the established pattern of background radioactivity.

Table 1. Annual range of the gross beta activity concentrations $\left(\mathrm{mBq} \mathrm{m}^{-3}\right)$ in airborne particulates in Ireland for 1998-2003.

\begin{tabular}{|c|c|c|c|c|c|c|}
\hline Location & 2003 & 2002 & 2001 & 2000 & 1999 & 1998 \\
\hline Caherciveen & $0.08-0.95$ & $0.07-0.76$ & $0.09-0.65$ & $0.07-0.68$ & $0.12-1.08$ & $0.09-1.02$ \\
\hline Clones & 0.07-1.19 & $0.09-0.65$ & $0.04-0.84$ & $0.08-0.41$ & $0.07-0.36$ & $0.07-0.95$ \\
\hline Clonskeagh & $0.09-0.76$ & 0.09-0.71 & 0.03-0.91 & $0.06-1.25$ & $0.12-1.27$ & 0.09-0.77 \\
\hline Dundalk & 0.06-0.89 & $0.09-0.81$ & 0.07-0.73 & $0.05-0.73$ & $0.08-0.31$ & 0.06-0.82 \\
\hline Galway & $0.10-0.79$ & $0.11-0.78$ & $0.05-0.94$ & $0.03-0.54$ & $0.09-0.57$ & $0.06-0.69$ \\
\hline Glasnevin & $0.09-1.14$ & $0.11-0.74$ & $0.03-0.62$ & $0.10-0.63$ & $0.11-0.49$ & 0.06-0.69 \\
\hline Midleton & 0.09-0.79 & 0.08-0.63 & $0.07-0.52$ & $0.10-0.45$ & $0.09-0.64$ & $0.08-0.74$ \\
\hline Mullingar & 0.08-0.82 & 0.06-0.75 & $0.03-0.63$ & $0.07-0.79$ & $0.09-0.74$ & $0.10-0.57$ \\
\hline Rosslare & 0.14-0.69 & $0.10-0.82$ & 0.13-0.81 & $0.08-0.54$ & $0.04-0.50$ & $0.06-1.33$ \\
\hline Mean $( \pm 1 \sigma)$ & $\begin{array}{l}0.28 \pm 0.17 \\
(n=386)\end{array}$ & $\begin{array}{l}0.26 \pm 0.16 \\
(n=415)\end{array}$ & $\begin{array}{l}0.25 \pm 0.13 \\
(n=415)\end{array}$ & $\begin{array}{l}0.24 \pm 0.13 \\
(n=357)\end{array}$ & $\begin{array}{l}0.26 \pm 0.12 \\
(n=350)\end{array}$ & $\begin{array}{l}0.25 \pm 0.15 \\
(n=438)\end{array}$ \\
\hline
\end{tabular}




\subsection{Results for the high volume particulate samples}

The high volume sampler, located at Beggars Bush in Dublin, has been fully operational since 1993. A summary of the results of all measurements carried out since 1993 are presented in Table 2 [1-5]. All of the caesium-137 activity concentration measurements made since 1993 are below $10^{-5} \mathrm{~Bq} \mathrm{~m}^{-3}$ with a mean over all years of $2.3 \pm 2.2 \mu \mathrm{Bq} \mathrm{m}^{-3}(n=26)$. The mean beryllium-7 activity concentration during this period is $3.0 \pm 1.6 \mathrm{mBq} \mathrm{m}^{-3}(n=42)$.

Table 2. Caesium-137 and beryllium-7 activity concentrations $( \pm 1 \sigma)$ in air at Beggars Bush (Dublin).

\begin{tabular}{|c|cccccc|}
\hline \multirow{2}{*}{ Radionuclide } & \multicolumn{7}{|c|}{ Sampling Period } \\
\cline { 2 - 7 } & $\mathbf{2 0 0 3}$ & $\mathbf{2 0 0 1 - 2 0 0 2}$ & $\mathbf{1 9 9 9 - 2 0 0 0}$ & $\mathbf{1 9 9 7 - 1 9 9 8}$ & $\mathbf{1 9 9 4 - 1 9 9 6}$ & $\mathbf{1 9 9 3}$ \\
\hline $\mathrm{Cs}-137^{-3}$ & $\begin{array}{c}1.3 \pm 1.0 \\
(n=4)\end{array}$ & $\begin{array}{c}2.2 \pm 2.6 \\
(n=5)\end{array}$ & $\begin{array}{c}3.8 \pm 3.4 \\
(n=5)\end{array}$ & $<2.7$ & $\begin{array}{c}2.0 \pm 1.9 \\
(n=8)\end{array}$ & $\begin{array}{c}2.3 \pm 0.7 \\
(n=4)\end{array}$ \\
\hline $\left.\mathrm{Be}^{-7}\right)$ & $\begin{array}{c}2.5 \pm 0.6 \\
(n=7)\end{array}$ & $\begin{array}{c}3.6 \pm 2.9 \\
(n=9)\end{array}$ & $\begin{array}{c}2.3 \pm 0.8 \\
(n=7)\end{array}$ & $\begin{array}{c}3.1 \pm 1.0 \\
(n=7)\end{array}$ & $\begin{array}{c}3.2 \pm 1.5 \\
(n=8)\end{array}$ & $\begin{array}{c}3.0 \pm 0.7 \\
(n=4)\end{array}$ \\
$\left.(\mathrm{mBq} \mathrm{m})^{-3}\right)$ & $(n=0.7)$ &
\end{tabular}

\section{KRYPTON-85 AIR MONITORING}

In addition to its EURATOM requirements, the RPII also maintains a sampling programme to monitor and evaluate the krypton-85 concentration in air at Clonskeagh, Dublin. The routine atmospheric krypton-85 monitoring at Clonskeagh was initiated in 1993.

\subsection{Krypton-85}

Krypton-85 (Kr-85) is a radioactive noble gas with a half life of 10.7 years. It is released into the atmosphere primarily during the reprocessing of nuclear fuel. There are two major nuclear fuel reprocessing plants in western Europe, at Sellafield on the northwest coast of England and at La Hague on the northwest coast of France. The annual discharges of krypton-85 from these two facilities, for the years 1989-2003 are presented in Figure 2.

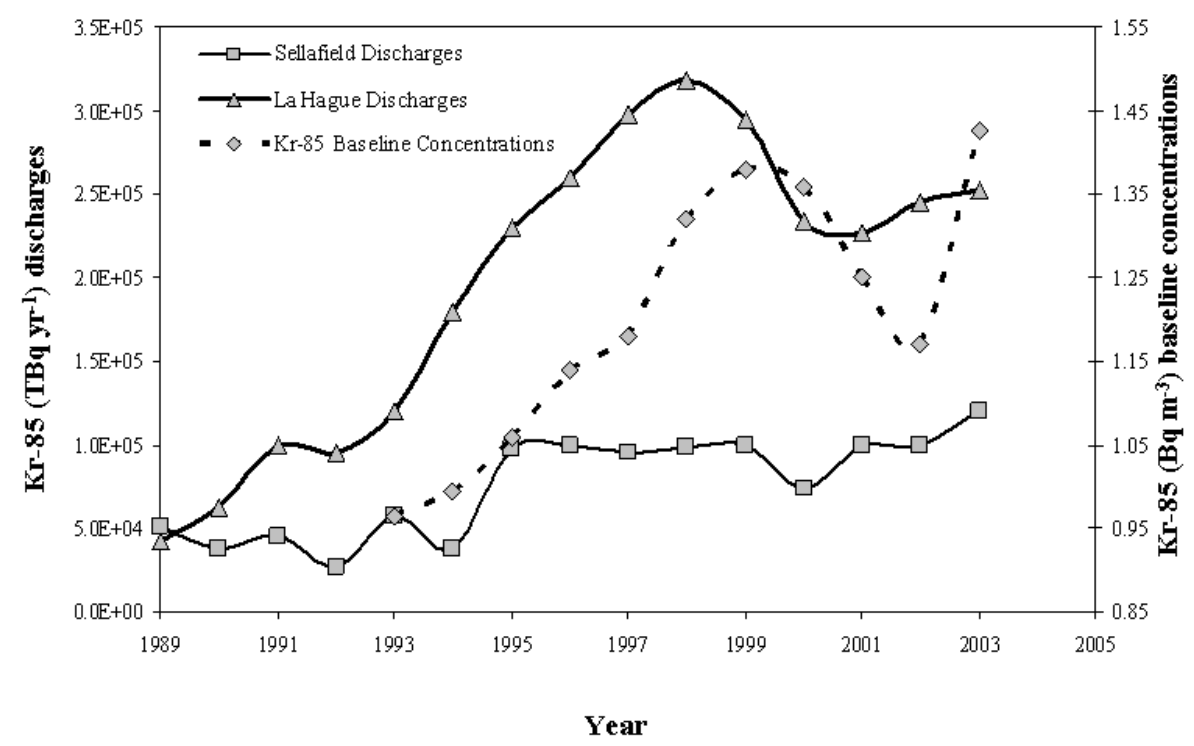

Figure 2. Krypton-85 discharges to the atmosphere from Sellafield and La Hague, 1989-2003. The baseline krypton-85 concentrations recorded at Clonskeagh (Dublin) since 1993 are included. 
It is clear that the annual discharges from La Hague are considerably greater than those from Sellafield, reaching a maximum of approximately $3.2 \times 10^{5} \mathrm{TBq}$ in 1998. The Cogema La Hague discharges decreased to an average of approximately $2.4 \times 10^{5} \mathrm{TBq}$ for 2000-2003. The discharges from Sellafield increased after 1994 with the commencement of the Thermal Oxide Reprocessing Plant (THORP) but have remained at approximately $1.0 \times 10^{5} \mathrm{TBq}$ since 1995 .

\subsection{Krypton-85 sampling and measurement}

The collection of a sample of krypton from the air is made using the technique developed at the University of Gent, Belgium [6]. Briefly, krypton-85 is sampled from air using a pump to draw the air over an activitated charcoal trap maintained at the temperature of liquid nitrogen. The krypton sample is transferred by distillation from the charcoal trap to a copper coil containing a molecular sieve. The copper coil is then sent to Belgium for analysis, which involves gas chromatographic separation of krypton gas followed by liquid scintillation counting to determine the krypton-85 concentration. Each air sample was collected over a two-hour period typically twice monthly

\subsection{Results of krypton-85 monitoring}

The results of measurements carried out at Clonskeagh since 1993 are presented in Figure 3 [1-5]. A number of relatively high krypton concentrations have been omitted from this plot and are given in Table 4 . The uncertainty on individual measurements is approximately $\pm 5 \%$ and all measurements have been corrected to the standard temperature and pressure (STP).

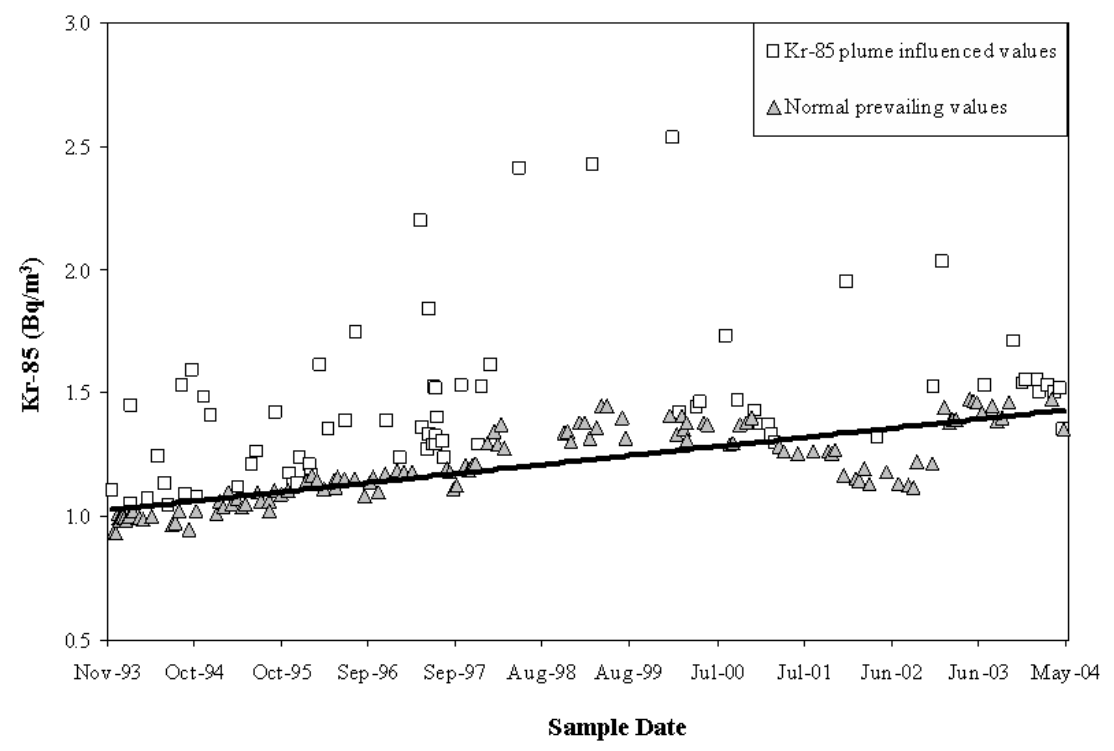

Figure 3. Krypton-85 in air at Clonskeagh (Dublin), 1993-2004.

Annual baseline concentration values for 1993 to 2003 inclusively have been calculated using the method of Howett and O’Colmáin [7]. In this approach, krypton concentration values, which are equal to, or less than, 1.10 times the minimum value measured in a given year, i.e. the minimum value plus twice the uncertainty in its measurement, are classified as normal prevailing values. All other values are assumed to be due to the passage of plumes of ${ }^{85} \mathrm{Kr}$. The baseline concentration value for a particular year is then taken to be the mean of the normal ${ }^{85} \mathrm{Kr}$ values. 
The krypton-85 data in Figure 3 have been classified as either normal prevailing or plume influenced. A linear trend line fitted to the normal prevailing values indicates an overall increasing trend in the krypton-85 concentrations since 1993.

The calculated baseline concentration values, given in Table 3 and included in Figure 2, follow the same trend as the annual discharges from Cogema La Hague reprocessing plant. It is evident that the discharge values and the baseline concentration values are out-of-phase by one year, with the discharge values leading the concentration values. For example, a peak in the baseline concentrations for 1999 follows the 1998 peak in the La Hague discharges. It is unclear how the Sellafield discharges affect the baseline concentrations because they remain relatively constant over the period under investigation. The Sellafield discharges show a temporary decrease in 2000 but this corresponds with reduced La Hague discharges.

Table 3. Annual mean and baseline krypton-85 concentrations $\left(\mathrm{Bq} \mathrm{m}^{-3}\right)( \pm 1 \sigma)$.

\begin{tabular}{|l|ll|}
\hline Year & Mean & Baseline \\
\hline 1993 & $0.98 \pm 0.06(7)$ & $0.96 \pm 0.03(6)$ \\
1994 & $1.24 \pm 0.64(26)$ & $0.99 \pm 0.02(13)$ \\
1995 & $1.11 \pm 0.09(23)$ & $1.06 \pm 0.03(15)$ \\
1996 & $1.32 \pm 0.42(21)$ & $1.14 \pm 0.03(14)$ \\
1997 & $1.34 \pm 0.23(28)$ & $1.18 \pm 0.03(11)$ \\
1998 & $1.46 \pm 0.35(10)$ & $1.32 \pm 0.03(13)$ \\
1999 & $1.50 \pm 0.35(9)$ & $1.38 \pm 0.05(8)$ \\
2000 & $1.57 \pm 0.59(21)$ & $1.36 \pm 0.04(13)$ \\
2001 & $1.33 \pm 0.19(13)$ & $1.25 \pm 0.04(8)$ \\
2002 & $1.73 \pm 1.81(13)$ & $1.17 \pm 0.04(9)$ \\
2003 & $3.25 \pm 5.56(19)$ & $1.43 \pm 0.04(12)$ \\
2004 & $4.86 \pm 9.53(8)$ & $1.42 \pm 0.08(2)$ \\
\hline
\end{tabular}

Since the commencement in 1993 of the krypton program a small number of elevated krypton values $\left(>3 \mathrm{~Bq} \mathrm{~m}^{-3}\right.$ ) have been observed and are given in table 4. For each of these values a backward trajectory was performed using the National Oceanic and Atmospheric Administration (NOAA) Hybrid Single-Particle Lagrangian Integrated Trajectory (HYSPLIT) model [8]. The HYSPLIT backward trajectory shows an aerial view of the path(s) an air parcel(s) took in order to reach its destination, and a vertical view of its movement at different altitudes. A selection of these trajectories are presented in Figure 4.

Table 4. Elevated krypton concentrations recorded at RPII.

\begin{tabular}{|l|cc|}
\hline Date & Kr-85 $\left.\mathbf{( B q ~}^{-3}\right)$ & Wind direction \\
\hline $11 / 05 / 1994$ & 4.3 & $\mathrm{E} / \mathrm{SE}$ \\
$10 / 12 / 1996$ & 3.0 & $\mathrm{E}$ \\
$29 / 03 / 2000$ & 3.9 & $\mathrm{NE}$ \\
$30 / 10 / 2002$ & 7.7 & $\mathrm{E} / \mathrm{NE}$ \\
$20 / 03 / 2003$ & 3.3 & $\mathrm{~W} / \mathrm{NW}$ \\
$16 / 04 / 2003$ & 24.8 & $\mathrm{SE}$ \\
$11 / 11 / 2003$ & 9.7 & $\mathrm{~S} / \mathrm{SE}$ \\
$28 / 05 / 2004$ & 28.4 & $\mathrm{~S} / \mathrm{SE}$ \\
\hline
\end{tabular}



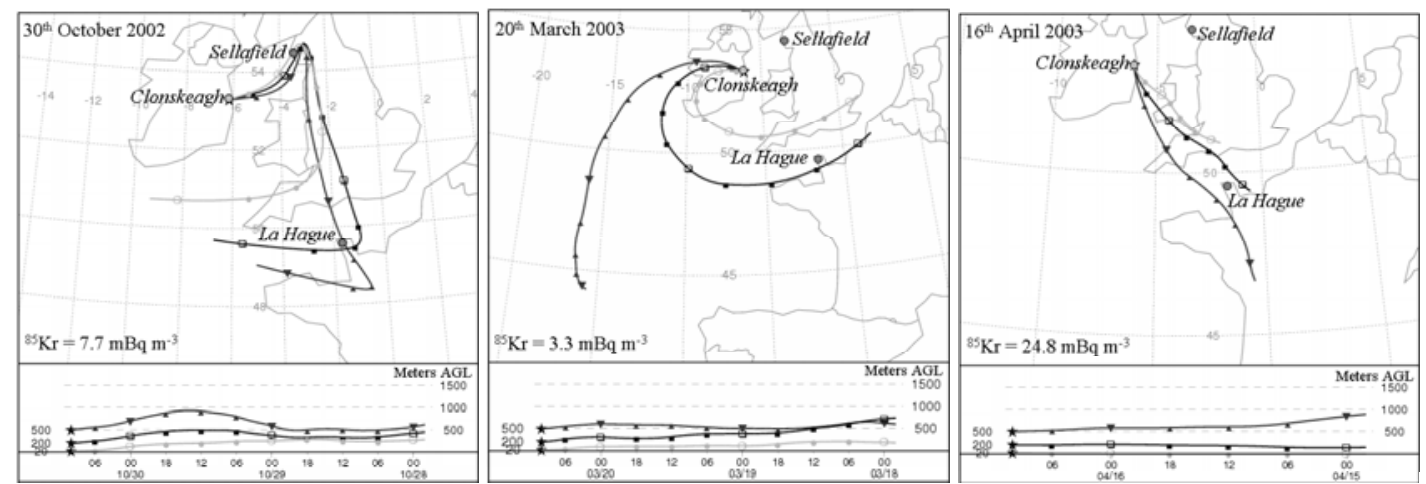

Figure 4. NOAA HYSPLIT model backward trajectories for air parcels arriving at Clonskeagh (Dublin) at 10am on (from left to right) $30^{\text {th }}$ October 2002, $20^{\text {th }}$ March 2003 and $16^{\text {th }}$ April 2003. The vertical view at the bottom of each map shows the height above model ground level (AGL) of the air parcel measured at these corresponding tick marks.

The prevailing wind direction at Clonskeagh is from a west-southwest direction with few easterlies or south easterlies. However, for the elevated krypton values given in Table 4, sampling occurred during or after the passage of an easterly or south easterly wind. The HYSPLIT back trajectories clearly show that the krypton-85 in these samples emanates from either Sellafield (to the East) or La Hague (south East). The direct route which the air follows would not allow for significant dilution prior to sampling in Ireland.

\section{CONCLUSION}

The gross beta activity concentrations in airborne particulates sampled at nine stations for the period 1998 to 2003 have been found to be consistently low. The activity levels observed were insignificant from a radiological protection perspective [5]. Similarly, the analysis of airborne particulates taken with the high volume air sampler has not shown any abnormal readings. The caesium-137 levels observed are consistent with global fallout levels at these latitudes. A new high volume air sampler is currently being commissioned and will increase the number of caesium-137 and beryllium-7 results from a current maximum of 6 per annum to a minimum of 26 per annum.

Analysis of the krypton-85 data from 1993 to present clearly indicates the influence of the Cogema La Hague reprocessing plant on the krypton-85 concentrations observed in Ireland. The extent to which Sellafield discharges influence these concentrations is unclear as they remain relatively constant over the period of investigation.

\section{Acknowledgments}

The authors gratefully acknowledge the NOAA Air Resources Laboratory (ARL) for the provision of the HYSPLIT transport and dispersion model and READY website (http://www.arl.noaa.gov/ready.html) used in this publication.

\section{References}

[1] Sequeira S., Pollard D., Hayden E., Dunne B., Colgan P.A. and Cunningham J.D., "Environmental Radioactivity Surveillance Programme, 1988-1989” Nuclear Energy Board, Dublin, (1990) pp.32.

[2] Sequeira S., Pollard D., Hayden E., Fegan M., O’Colmáin M., McGarry A. and Cunningham J.D., "Environmental Radioactivity Surveillance Programme, 1990-1993”, RPII-95/2, Radiological Protection Institute of Ireland, Dublin, (1995) pp. 23. 
[3] Pollard D., Smith V., Howett D., Hayden E., Fegan M., O’Colmáin M. and Cunningham J.D., “Environmental Radioactivity Surveillance Programme, 1994-1996”, RPII-97/2, Radiological Protection Institute of Ireland, Dublin, (1997) pp. 23.

[4] Sequeira S., Pollard D., Smith V., Howett D., Hayden E., Fegan M., Dowdall A., Brogan C., O’Colmáin M. and Cunningham J.D., "Environmental Radioactivity Surveillance Programme, 1997 and 1998”, RPII-99/2, Radiological Protection Institute of Ireland, Dublin, (1999) pp. 25.

[5] Ryan T.P., Sequeira S., Smith V., Fegan M., Hayden E., Murray M., Dowdall A., Howett D., Pollard D. and Cunningham J.D., "Environmental Radioactivity Surveillance Programme, 1999 and 2000”, RPII-02/2, Radiological Protection Institute of Ireland, Dublin, (2002) pp 33.

[6] Janssens A., Buysse J., Raes F. and Vanmarcke H., Nucl. Instrum. Methods Phys. Res. B 17 (1986) 564-567.

[7] Howett D. and O’Colmáin M., J. Radiol. Prot., 18 (1998), 15-21.

[8] Draxler, R.R. and Rolph, G.D., 2003. HYSPLIT (HYbrid Single-Particle Lagrangian Integrated Trajectory) Model access via NOAA ARL READY Website (http://www.arl.noaa.gov/ready/hysplit4.html). NOAA Air Resources Laboratory, Silver Spring, MD. 